\title{
A Phenomenological Study of Factors Influencing the Gender Gap in Physics and other STEM-Related Fields
}

\section{Dr. Teresa L. Larkin, American University}

Teresa L. Larkin is an Associate Professor of Physics Education and Faculty Liaison to the Pre-engineering Program at American University. She received her Ph.D. in Curriculum and Instruction with emphasis in Physics and Science Education from Kansas State University. Dr. Larkin is involved with Physics Education Research (PER) and has published widely on topics related to the assessment of student learning in introductory physics and engineering courses. Noteworthy is her work with student writing as a learning and assessment tool in her introductory physics courses for non-majors. She has been an active member of the American Society for Engineering Education (ASEE) and the American Association of Physics Teachers (AAPT) for over 25 years. Dr. Larkin served on the Board of Directors for ASEE from 1997-1999 as Chair of Professional Interest Council (PIC) III and as Vice President of PICs. Dr. Larkin has received numerous national and international awards including the ASEE Distinguished Educator and Service Award from the Physics and Engineering Physics Division in 1998. Dr. Larkin received the Outstanding Teaching in the General Education Award from AU in 2000. In 2000 - 2001 she served as a National Science Foundation ASEE Visiting Scholar. Dr. Larkin is the author of a book chapter published in 2010 entitled "Women's Leadership in Engineering" in K. O'Connor (Ed.) Gender and Women's Leadership: A Reference Handbook (Vol. 2, pp. 689 - 699). Thousand Oaks, CA: SAGE Publications. In 2013 her paper entitled "Breaking with Tradition: Using the Conference Paper as a Case for Alternative Assessment in Physics" received an award for best paper in a special session entitled Talking about Teaching (TaT'13), at the 42nd International Conference on Engineering Pedagogy (IGIP) held in Kazan, Russia. Dr. Larkin can be reached at: tlarkin@american.edu.

\section{Victoria "Tori" Vogel, American University}

Tori Vogel is a May 2014 graduate of American University. She attained her degree in Sociology with a minor in Applied Physics. In her studies she has worked to explore the various intersections between sociology and physics. In particular, she has conducted research on cochlear implants and their impact on the deaf community. In addition, she is actively pursuing a gender study of the sociological implications of factors leading to a career choice in STEM. On campus, Tori has held leadership roles within student groups. These roles include serving for two years as Vice President of Students Fighting Homelessness and Hunger and serving as President of the Downtown Touring Fellowship. While attending American University she worked for nearly every office of Student Affairs, was part of the university's Honors program, Alpha Kappa Delta the International Sociology Honor's Society, and is a member of the National Society of Collegiate Scholars. Off campus she is part of a synchronized figure skating team. Tori aspires to pursue a career in social justice through social entrepreneurship. Tori Vogel can be reached at vv4118a@american.edu or tori.vogel.4@gmail.com. 


\title{
A Phenomenological Study of Factors Influencing the Gender Gap in Physics and other STEM-Related Fields
}

\author{
"I was always very interested in science, and I knew that for me, science was a better \\ long-term career than tennis. So I decided on science when I was in college." \\ -Sally Ride, first American woman in space
}

\begin{abstract}
Current reports on the gender gap in STEM suggest factors influencing career choice between the sexes are not inevitable. Recent decades have documented a clear change in the gender makeup of some STEM disciplines. However, in many areas, the gap has persisted with little or no change in the number of women choosing to pursue a career in a STEM-related field such as Physics. According to recent AIP reports ${ }^{1,2}$, women comprise $21 \%$ of undergraduate, $21 \%$ of graduate, and $19 \%$ of doctoral degrees in Physics. Many factors have been studied by scholars as contributing to the dearth of women in Physics and STEM ${ }^{3-8}$. Factors including the lack of role models, discouragement from the media, sex difference in cognitive skill, and unpleasant experiences related to gender-bias in the classroom have all been suggested as potential reasons why women tend not to pursue a career in Physics or other STEM field. Suggestions from some scholars also indicate that women often tend to seek out careers in which they feel they can make a difference. Unfortunately, the size of the gap in many areas has reached a plateau that hasn't appeared to shift significantly over time.

This phenomenological study will look at how individual perceptions of STEM (with an emphasis on Physics) as a career option may influence academic and professional pursuits. To that end, formal interviews with practicing professionals and college students from a range of disciplines will be used as a primary data collection tool. This paper will provide a synthesis of the empirical data collected through these formal interviews. Factors that emerge from this synthesis as having a significant influence on one's perception of STEM as a career choice will be further examined and discussed. By focusing on individual perceptions, this study aims to contribute to the existing empirical database of factors that influence career choice and perpetuate the gender gap in STEMrelated fields such as Physics. The themes that emerge may stimulate further research on this topic and provide suggestions for best practices that may contribute to closing the gap.
\end{abstract}

\section{Introduction}

What do you want to be when you grow up? From a young age children are prompted to consider this question as they contemplate their choices for the future and ultimately for their ideal career. Young boys are often perceived to be the ones that like to tinker with mechanical toys, take things apart, and put them back together. Young girls, on the other hand, are seen in a more nurturing light, even at an early age. Young boys and girls can carry these stereotypical perceptions with them, often throughout their entire lives. 
Just a century ago, the common perception was that a career in STEM was probably bestsuited for men. While this perception has gradually changed over the past 100 years, the fundamental picture of many STEM fields remains predominantly masculine. Women began slowly populating college-level engineering and other STEM classrooms in the 1950s and 1960s; however, the numbers of women were small compared to those of their male counterparts. It was not until the women's movement in the 1970s that women began entering these fields in greater numbers.

The decision to pursue a career is often based largely on individual perceptions of what the field will be like. In addition, many factors contribute to the formation of these perceptions. Despite the fact that most people from the millennial generation will have as many as fifteen-twenty different jobs in their lifetime, college students limit their academic learning to one or two majors and move forward focused on their perception of a career path before their work experience has begun ${ }^{18}$.

A broad stereotype of careers in Physics and STEM (in general) are that they are harder and only fit for the very intelligent. These areas have also statistically been male dominated fields. Though many programs exist to encourage and support women in their careers, the gender gap remains unchanged. In this study, we focus on the perception that women and men have of a career in Physics and STEM. Moreover, we look at how these perceptions may relate to the number of women pursuing these types of careers.

\section{Review of Related Research}

Within the college setting, women continue to be underrepresented in all areas of the natural sciences, engineering, and mathematics. This underrepresentation includes women on both sides of the academic desk and those in leadership roles within the academy. Considerable discussion has taken place within the science and engineering communities regarding the "glass ceiling" so often encountered by women aspiring to leadership roles in these disciplines. Within engineering and science professions, the "glass ceiling" is thought of as an invisible barrier that prohibits women from advancing in their professional careers.

If a woman is successful in getting through various barriers and roadblocks such as those described by Tobias, they often run into other obstacles as they move forward in their careers $^{6}$. In her study of why some choose to do science while others do not, she described a group of students she refers to as "second tier" students. Tobias cautioned that second tier is not to be confused with second rate. She suggested that the term second tier is a "...loose hypothetical construct, which includes a variety of types of students not pursing science in college for a variety of reasons" (p. 14). These students are often very capable of doing science; they simply choose not to. Tobias propounded that reasons one might have for not choosing science as a pathway to a career may be grounded in different types of individual learning styles, expectations, degrees of discipline, and different "kinds of minds" compared to those who traditionally enjoy and succeed in science. 
Women have historically faced many challenges on the road to making a career choice, particularly when that choice is to enter a male-dominated field such as STEM. Tobias has been critical of introductory college science courses and has argued that typical classrooms are "... competitive, selective and intimidating, and designed to winnow out all but the 'top tier'... there is little attempt to create a sense of 'community' among average students of science" (p. 9). These types of classroom experiences perhaps play a role in the formulation of one's perception of a career in STEM.

One notable woman to effectively put a crack in the science and engineering glass ceiling was Eleanor Baum. An electrical engineer by training, in 1987 she became the Dean of Engineering at Cooper Union. At that time, Baum simultaneously made a dent in the history books and put a crack in the glass ceiling as the first woman to achieve a leadership position as dean of an engineering program in the United States. In addition, in 1994 Baum became the first woman president of the American Society for Engineering Education (ASEE). Not only were these distinctions a significant step for her own career, they represented a noteworthy message to all women engineers and scientists throughout the country. The message was simple. It was definitely possible for women to put a crack in the ceiling. While cracking the ceiling may be possible, we have still not seen a measurable increase in the number of women choosing to pursue a career in most areas within STEM. Moreover, the number of women in leadership positions remains quite small.

There has been an extensive amount of information documented and studies published regarding the gender gap as it pertains to the number of women pursuing STEM fields in academia and as a career choice. Research studies, both quantitative and qualitative have continued to suggest that there is the potential for gender bias in nearly every aspect of obtaining and maintaining a STEM career ${ }^{5,8}$. From early childhood classroom experiences to $\mathrm{PhD}$ lab experiences to professional hiring decisions, there are welldocumented examples of gender bias and discrimination ${ }^{3-8}$. Perhaps one of the most researched topics relates to the experiences that undergraduate women have in terms of battling social factors to attain STEM degrees ${ }^{5}$.

In addition to those mentioned earlier, several arguments have been suggested to help explain the gap that exists in the number of women pursuing academic studies and careers in STEM related areas. The lack of role models, discouragement from the media, sex difference in cognitive skill, and unpleasant experiences related to gender bias in the classroom have all been suggested as potential reasons why women tend not to pursue a career in Physics or other STEM fields. Though this list is not exhaustive, these examples arise as most prominent in the literature in terms of helping to expose plausible reasons for the gender gap.

Given the shortage of female role models, Larkin suggests that mentoring can take on other forms within a campus environment ${ }^{12}$. Looking at faculty ranks, associate and full professors are often expected to mentor their junior assistant professor colleagues. This expectation puts an extra load on the limited number of women currently holding those higher ranks within the academy. Effective mentoring can play a pivotal role, especially 
as one moves through the ranks within the academic arena. Regardless of numbers, it is important for women in faculty and other leadership positions to remain open to being an advocate for other women aspiring to take a walk on the leadership path.

Halpern suggests considering whether the lack of women in science is a social problem at all. She notes that no one ever questions why so few men are pursuing a career in nursing. She further asserts that there is an underlying assumption that men simply do not want to be nurses. This choice is not due to the fact that there is some type of gender bias against men who choose to pursue a career in nursing ${ }^{7}$. Documented cases of gender discrimination exist for women pursuing a career in Physics and STEM but Halpern's viewpoint helped to focus our study on individual perceptions of a STEM career. Instead of focusing on factors such as discrimination, we chose to focus on whether there is a difference between women and men in terms of their basic level of desire for a career in STEM. Moreover, how do individual perceptions differ between women and men in terms of making their career choice.

Additional studies have shown that women tend to do better than men on science and mathematics tests at the high school level. As the academic level increases, the achievement of women does not drop; however, the number of females choosing to take science and math courses does. This fact suggests that women are not less-equipped to handle the more difficult and challenging material covered in the advance science and mathematics ${ }^{8}$. The troubling fact is that there remains a significantly smaller number of women choosing to pursue advanced studies in these areas. It might be inferred that outside sociological forces such as gender discrimination and cultural expectations noted by many female scientists have a large impact on the number of women leaving the field ${ }^{9}$.

Recently, potential pathways to engage more women in STEM such as changing the classroom setting and establishing more networks for mentorship have been suggested in the literature ${ }^{3,8}$. Programs have been established to address the gender gap in science and more scholarships have been created to encourage women's participation. Businesses such as L'Oréal Foundation have dedicated research grant opportunities for women scientists $^{19}$. There are other companies such as the recently popular GoldieBlox that aim to engage young women in technical skills, college clubs promoting women in science, and professional associations dedicated to supporting women in STEM fields ${ }^{11}$. Despite best efforts, to date, there has been no definitive increase in the number of women represented within most branches of STEM.

\section{Motivation for the Study and Underlying Research Questions}

Many studies have been conducted that have explored the reasons underlying the perceived gender gap in STEM. There is an abundance of quantitative research documenting that the number of women students, educators, and professionals in STEM fields to be less than the number of men ${ }^{1-2,15}$. Furthermore, there is a considerable amount of research regarding the stereotypes that exist related to women in science classrooms, hiring decisions, and publication in research journals $\mathrm{s}^{7-8,16}$. For example, for 
the past 35 years, Jacquelynne Eccles and her colleagues have been studying issues surrounding the relatively low numbers of women researchers in science, engineering, and math ${ }^{17}$. While strides have been made over the past 3-4 decades to increase female participation in engineering and physical science careers, significant work remains. Eccles reports that average enrollments of women in engineering bachelor's degree programs increased from approximately 3 percent in the 1970s to approximately 18 percent in the 1990s, partly because of the development of intervention programs to increase female participation in that time period.

The purpose of this study was to take an updated sample of college students and professionals to see if their perceptions of STEM careers had changed in a manner not previously reported in the literature. An in-depth study was conducted in 2000 regarding the large number of students that were leaving academic science tracks for other majors. After data collection from seven universities, the results showed that a disproportionate number of students leaving the science major track were women and other minorities ${ }^{5}$.

As we pursued our study of the well-documented gender gap in many areas within STEM, the following research questions emerged:

- Do perceptions of STEM influence individuals in their decision to pursue or not to pursue careers in STEM-related fields?

- Moreover, is there a generational difference in the perceptions of a career in STEM? If so, what are the factors influencing those differences?

With these questions we hoped to understand whether there were any significant recent changes in individual perceptions of STEM and if so, how these changes might have an effect on career choice. Further, we aimed to examine the intersection of age between professionals and students to determine whether there was a shift in individual perceptions of STEM and; if so, how this shift may have influenced the career choices of individual participants.

Our working hypothesis was that factors leading an individual to choose STEM as a career or as an academic path of study are linked to their overall perceptions of STEM.As a result, individual perceptions will play a significant role in career choice. In the next section we provide an overview of our research strategies and methods of data collection.

\section{Overview of Study and Research Methods}

This qualitative study was conducted during the Fall 2013 semester. The process of developing this study was aligned closely with our research questions. In the subsections that follow we describe the setting for the study, its participants, the structure of the interviews conducted, along with the corresponding method of data analysis.

\section{Setting for the Study and Description of Participants}

American University is located at an urban center. The ratio representing the approximate 
number of female and male constituents is 60:40. The larger number of female students follows the national trend, which suggests that more women are attending college now than men. Given this fact alone, the continued shortage of women in STEM-related fields is discouraging.

As a small-to-mid-sized university, the collective student population of American University is representative of 130 countries and all 50 states. There are five academic schools within the university with over 60 undergraduate majors available. With such a mix of diverse academic options, the setting encompasses a wide range of student perspectives.

In terms of its faculty, 95\% of full-time teaching faculty at American University holds the highest degree in their field. The student-faculty ratio is approximately 12:1. As required by its robust general education program, all students are required to complete two courses from within the various STEM departments on campus as well as a basic math course.

To analyze the perceptions of students of a career in STEM, it was important to collect a wider framework for the empirical data. The majority of subjects originated from the 300-level, Modern Physics course. Because this course is required of every physics major, minor, and applied physics minor, there was a wide diversity in terms of the backgrounds class participants. Some students were following the BS track while others were following the track for the Physics minor or Applied Physics minor.

For this study 24 participants were interviewed. Figures 1 and 2 illustrate the composite demographics of the students and professionals interviewed.

\section{Student Participants}

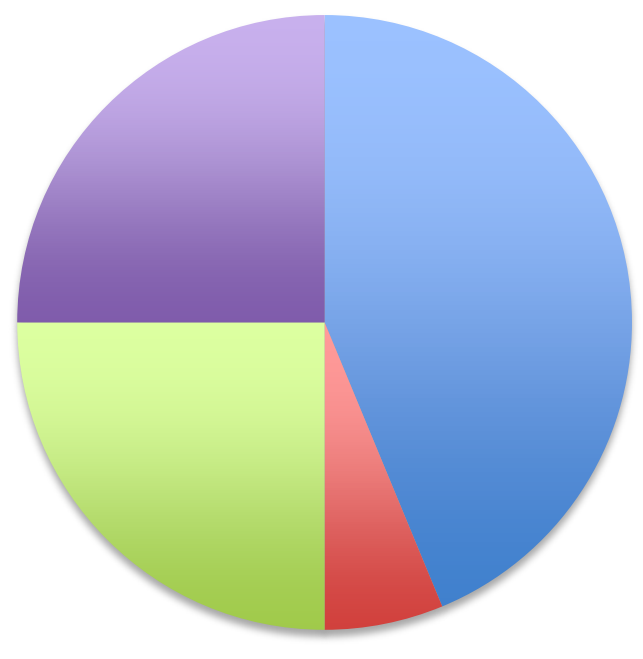

Male in STEM

Male Non-STEM

Female STEM

- Female Non-STEM

Figure 1. Student participants by gender and STEM affiliation.

Of the 24 participants, 17 were students. The average age range of students interviewed were 21 years old. Responses were separated by gender and academic major to assist in 
allowing trends and common themes to emerge.

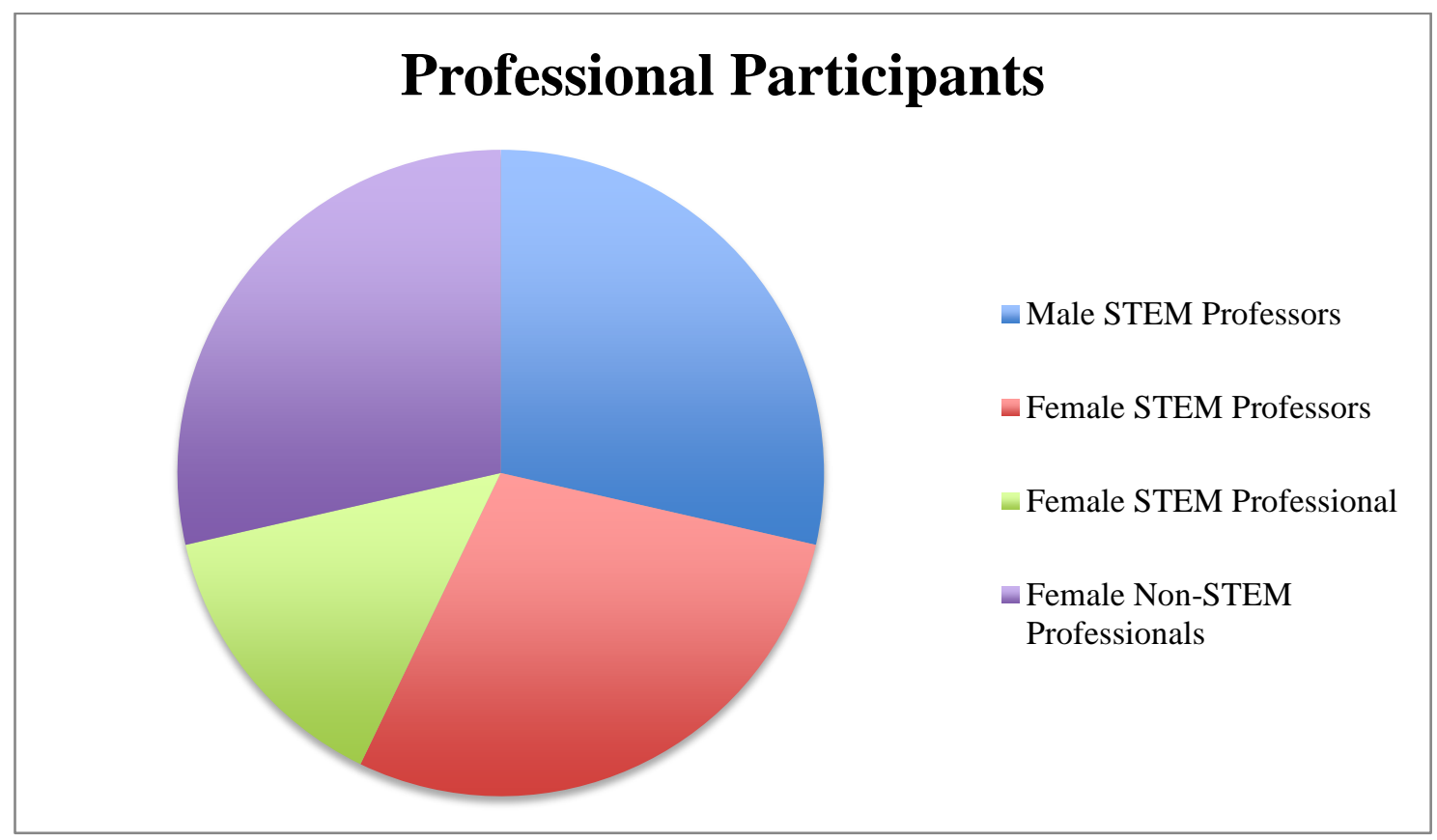

Figure 2. Professional participants by gender and career affiliation.

Figure 2 illustrates the breakdown by gender and career affiliation of the professionals interviewed. The remaining 7 interviews were of the professionals who participated in the study. The average age range of professionals interviewed were 32 years old.

Interview responses were further separated by gender and whether their academics or careers were related to STEM. This separation allowed for a straightforward analysis of emerging themes.

\section{Data Collection}

Our data collection methodology involved the creation and use of a set of semi-structured interview questions. To that end, a set of carefully crafted set of interview questions was developed. The thrust of the questions remained essentially identical, with the wording modified slightly based on whether the interviewee was a student or a practicing professional. The corresponding set of interview questions for each population of participants can be found in Appendices A and B. Each interview was audio recorded and then later transcribed.

Transcribed interviews were rearranged into a master file that separated each response by question. To separate the identity of the participant from their response, each interviewee was given a code letter. After the data was organized, responses were first analyzed to search for emergent themes. The most relevant questions and the data accompanying them were printed out for further analysis. 


\section{Preliminary Results}

For this paper, we present the results from three of our interview questions for students and two for professionals. A complete list of questions can be found in the appendices. We deemed these student questions and the corresponding interview data collected as being the most relevant to our immediate research questions:

2. What factors do you feel most influenced your selection of your current major? (i.e. a teacher, a parent, a friend, enjoyment of math and science in high school, etc.)

5. In more general terms, how do you perceive a career in STEM?

6. The lack of role models, discouragement from the media, sex difference in cognitive skill, and unpleasant experiences related to gender-bias in the classroom have all been suggested as potential reasons why women tend not to pursue a career in Physics or other STEM field. Do you feel that any of these factors played a role in your decision to or not to consider a career in STEM? In addition, were these factors a result of observations you made or were they a result of direct or indirect experiences?

Figure 3 represents a summary of student responses to Question 2 (i.e. factors that influenced selection of current major). Responses were arranged according to the student's major with a third category for those who had changed majors either from STEM to non-STEM, from non-STEM to STEM, or within other non-STEM areas. The figure includes general factors that influenced a student's selection of current major but does not account for the time at which these factors were influential.

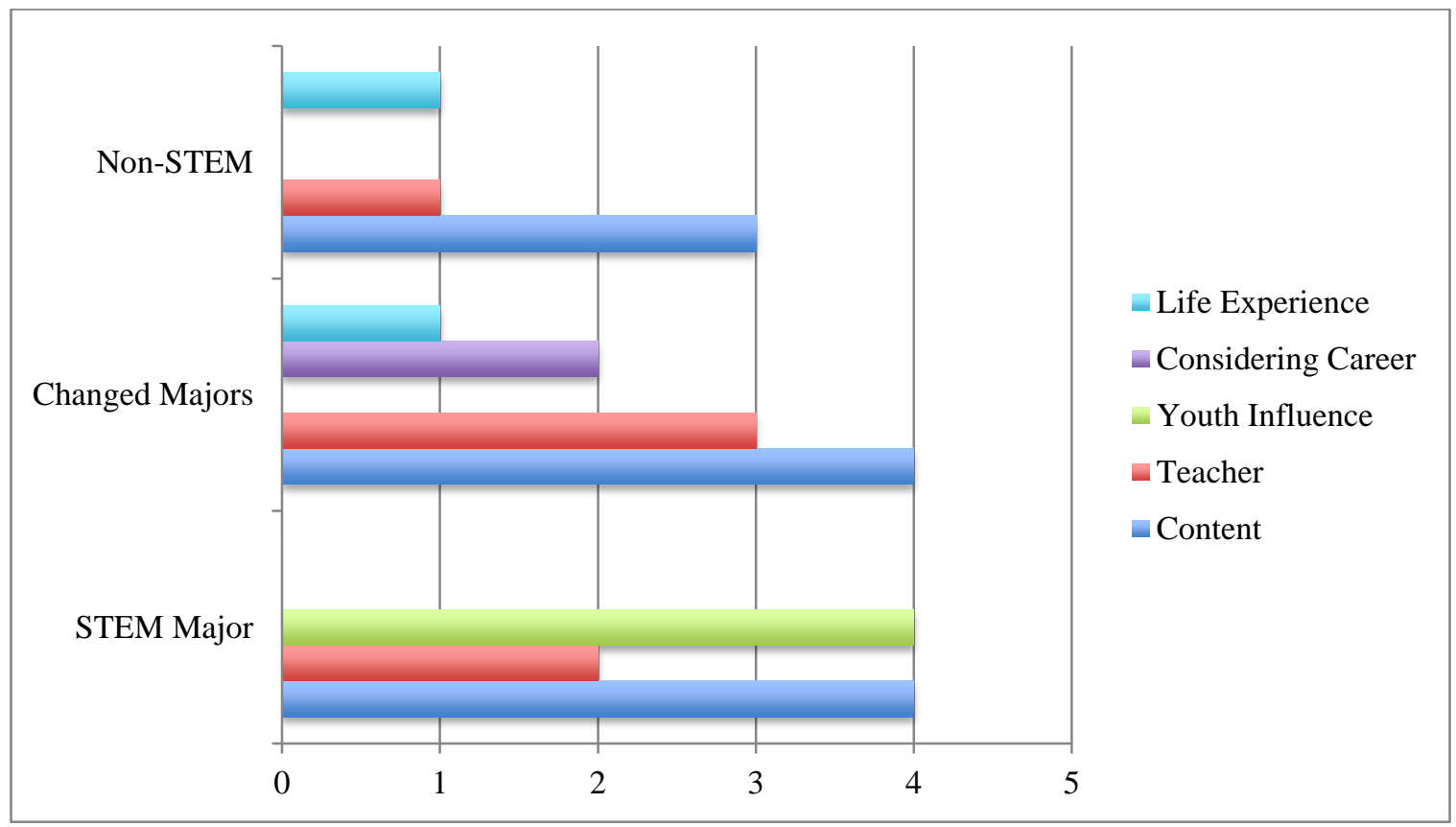

Figure 3. Factors influencing student selection of current major. 
Figure 4 provides a summary of student responses to Question 5 (i.e. how they perceived a career in STEM). The question was open ended yet all participants chose to use the words "hard" and "fulfilling."

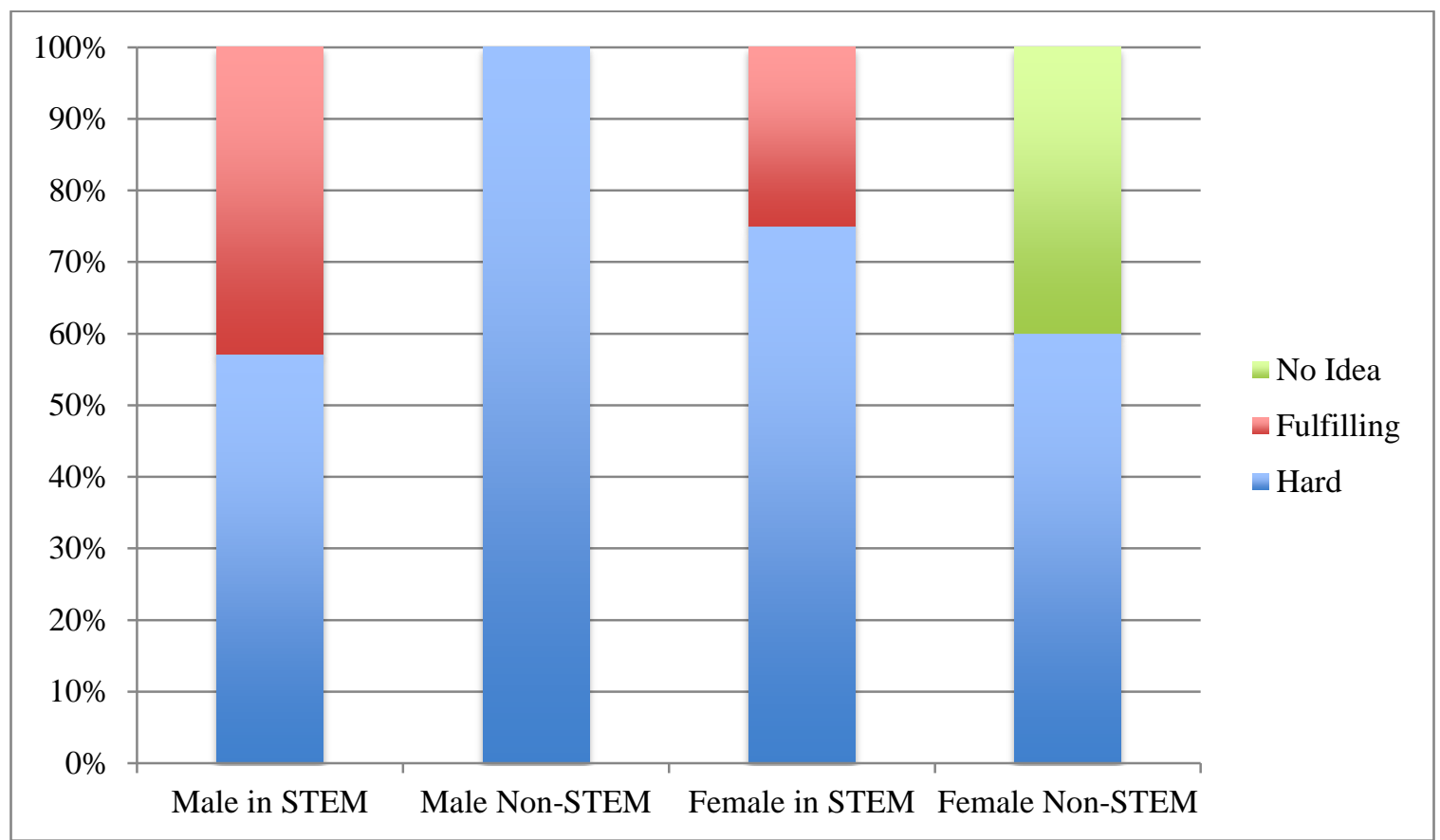

Figure 4. Student perceptions of a career in STEM.

Figure 5 displays student responses to Question 6 (i.e. what factors they believed most influenced the gender gap of women in STEM). For this question we encouraged participants to identify as many factors as they felt relevant to the question. While there were several factors listed in the question participants were encouraged to add any other factors that came to mind.

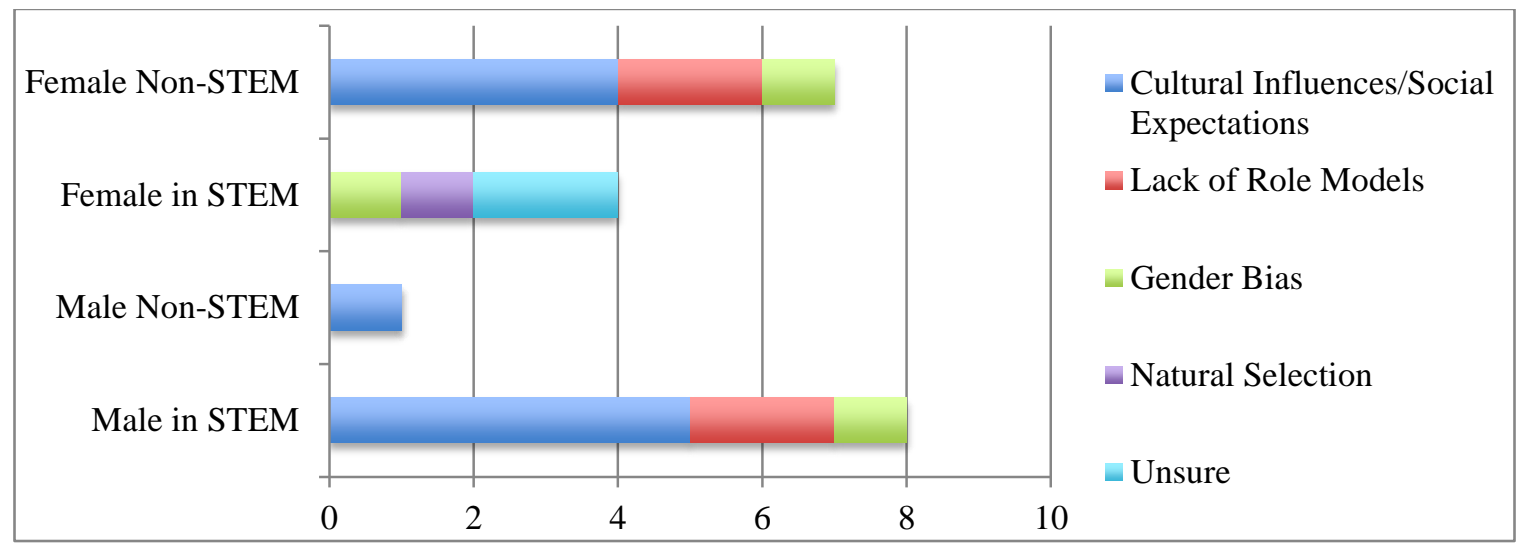

Figure 5. Student perceptions regarding the existence of the gender gap in STEM.

In terms of responses from professionals we focused on the following two questions, which paralleled those asked of the student participants: 
3. There is presently an abundance of research that shows that the lack of role models, discouragement from the media, sex differences in cognitive skill, and unpleasant experiences related to gender-bias in the classroom have all been suggested as potential reasons why women tend not to pursue a career in Physics or other STEM fields. Do you feel that any of these factors played a role in your decision to or not to consider a career in STEM? In addition, were these factors a result of observations you made or were they a result of direct or indirect experiences?

5. Do you perceive science (in general) to be a field that engages society? Why or why not?

Figure 6 represents professionals' responses to question 3 (i.e. whether they directly or indirectly experienced gender discrimination in STEM). Unlike the student responses, many professionals had personal stories about discrimination they had encountered directly or indirectly when they were either a student or on the job. Their responses tended to focus more on their personal experiences as they related to this question.

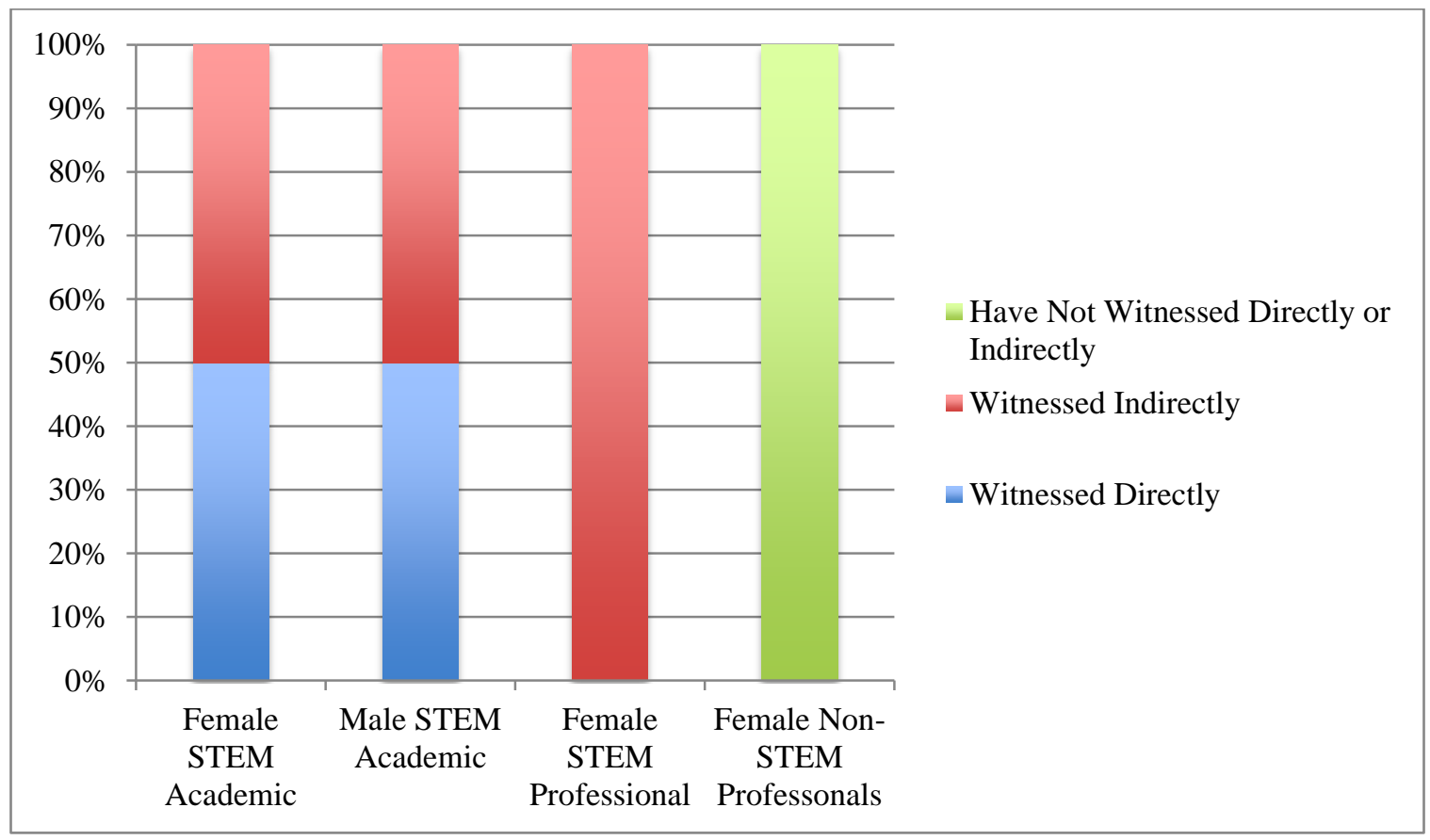

Figure 6. Professional experience witnessing gender discrimination in STEM.

Figure 7 represents professionals' responses to question 5 (i.e. whether they perceived science to be engaging to society). 


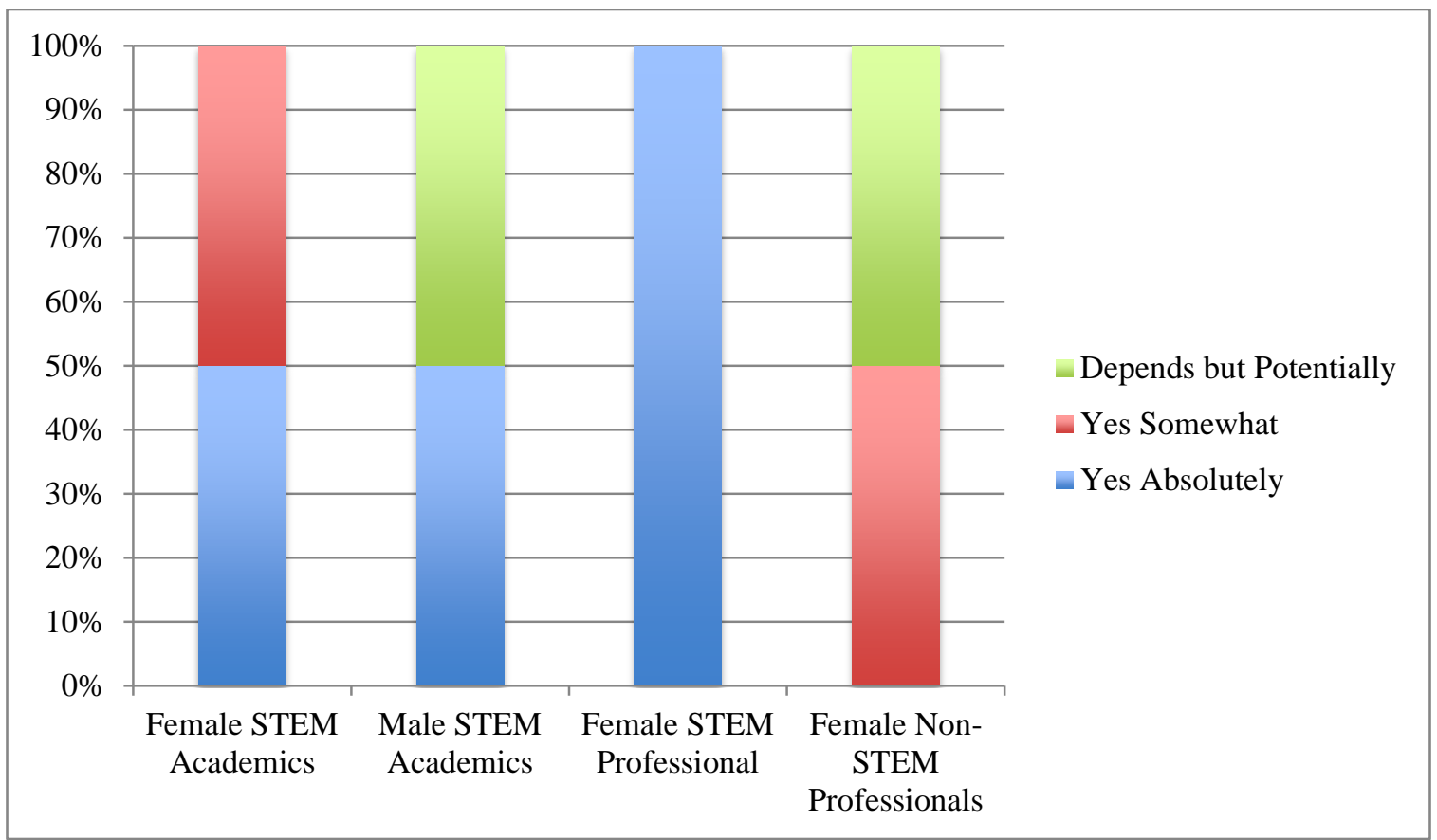

Figure 7. Professional perception of science's engagement in society.

In the section that follows we provided a synthesis of the results presented in the above tables. In addition, we provide a discussion of possible implications for further study.

\section{Discussion of Results and Implications for Continued Research}

Common themes that resulted from the data collected questions suggested a difference between how individuals that are studying versus not studying STEM subjects were influenced in terms of their current academic career path. Figure 3 shows that different factors influence individual selection of STEM, Non-STEM majors, and those who switch majors within college. An overwhelming majority of those pursuing a degree in a STEM related field were influenced at an early age to consider a STEM career. An equal number of those studying STEM and non-STEM fields were influenced by the content.

In Figure 4, the perception of a STEM career from all participants was that it would be a difficult path to follow. The interesting trend that occurred which could not be demonstrated within a figure was the different personal reactions (especially those of women participants) to their perception that a career in STEM would be difficult. For those women pursuing a STEM degree, they noted that the experience was difficult and this was a reason they chose to pursue the degree. For women pursuing non-STEM degrees, four of them noted that they desired to be better in STEM classes but that they did not feel confident in their abilities. This emerging trend perhaps suggests that a lack of confidence is something that may be a factor in academic and career choice.

Furthermore, lack of confidence may be related to other external factors and would be an interesting feature on which to base a future study.

Looking at the results illustrated in Figure 5, male students studying STEM and non- 
STEM and women students studying non-STEM all noted that cultural bias was most influential in perpetuating the gender gap of women in science. Cultural bias can be described as the phenomenon of interpreting and/or judging an individual or group based on morals and values inherent to the culture one is living within. Male students in STEM and female students in non-STEM agreed that the lack of role models was an important factor influencing the gap of female students as well. Interestingly female students within STEM did not note cultural bias or lack of role models as a factor influencing the gender gap. Rather, despite acknowledging that the gender gap exists, the female STEM students interviewed were fairly uncertain what factors were actually influencing the gap even when pressed with further follow up questions. This element of the data is noteworthy in that the population of women outside of STEM believed that certain factors existed that influenced the gender gap. However, the women actively pursuing STEM did not identify or characterize these same factors. In fact, the women in STEM found it more difficult to pinpoint even a single factor that contributed to the gender gap.

Results from the data analyzed suggest that to pursue a STEM degree, individuals are influenced at a young age and later by the content of the classes. The perception of a career in STEM appears to be similar whether a student was in a STEM-related academic field or not. Students that are female or male not studying STEM believe cultural bias and lack of role models are the two largest factors influencing the gender gap. Women studying STEM cannot identify what factors are influencing other women from studying STEM.

Upon analysis of our results, we found that some indicators are consistent with previous research while others are not. The notion suggested by other researchers that suggested women and men view the field of science differently was unsupported by our research. Results presented here suggest that all participants had similar opinions of a career in STEM. Cultural bias and lack of role models are consistently cited as large factors influencing the gender gap in science and male participants along with female non-STEM participants noted these as factors ${ }^{5,7}$. The fact that in our study women in STEM did not pinpoint specific influences on the gender gap gives incentive for continued research. More research can be done to find out whether potential factors are not visible to women pursuing STEM at the undergraduate level or in a larger sample size if female students would be able to identify factors.

\section{Summary}

In summary, the broad perception of a STEM career appears to be similar across the wider student population. STEM subjects are perceived as being difficult. The reaction student participants had to learning a difficult subject though is either due to intrinsic motivation to continue or internally or externally driven prompts to try something new and different.

The data also revealed that there is a difference in how outsiders (either gender) of the STEM fields perceive women in science. Difficulties that outsiders perceive are not the same as those noted by women within these fields. This, along with the lack of 
confidence non-STEM women noted as to why they were not studying STEM subjects may provide additional fuel for further research.

The data supports the original research question but in an unexpected way. Our driving question was:

- Do perceptions of STEM influence individuals in their decision to pursue or not to pursue careers in STEM-related fields?

The individuals interviewed perceived STEM almost identically, regardless of academic discipline or gender, as being a field that is difficult to pursue. The reaction to the perception that the field is difficult influenced whether the student will pursue a career or not. Women who felt studying something difficult was exciting were pursuing a STEM major or minor. Conversely, women who were not pursuing a STEM degree and felt it was difficult cited their perceived personal inabilities as to why they were not pursuing study within the STEM domain.

Lebold \& Lebold have advocated the need to expand efforts to increase the number of tenured female faculty at college and universities throughout the country ${ }^{13}$. These researchers have also argued that closer cooperation with underrepresented and minority groups in engineering could also result in real breakthroughs in the engineering management "glass ceiling" The chilly climate women often face when entering science and engineering professions also needs some adjustment. Considering the current relatively low numbers of women in science and engineering fields, Zoli, et. al. have suggested that perhaps rather than conforming to the existing science and engineering climates in the professional academic setting, a transformation of these climates may be in order. Conceivably, existing perceptions of the various disciplines within STEM needs to be altered and expanded to become a better fit for more women.

\section{Acknowledgements}

The authors would like to give a special thank you to the interview participants for sharing their experiences and their time. We would also like to collectively thank a number of students and faculty from within the American University community for providing their thoughts and insights throughout the various phases of this study.

\section{Bibliography}

[1] http://www.aip.org/statistics/trends/reports/bachdemograph10.pdf, Accessed 18.10.13.

[2] http://www.aip.org/statistics/trends/reports/bachdemograph10.pdf, Accessed 19.10.13.

[3] Rosser, S. V. (Ed.). (1995). Teaching the majority: Breaking the gender barrier in science, mathematics, and engineering. New York: Teacher's College Press.

[4] National Academy of Sciences, National Academy of Engineering, and Institute of Medicine of the National Academies. (2007). Beyond bias and barriers: Fulfilling the potential of women in academic science and engineering. Washington, DC: The National Academies Press. 
[5] Seymour, E. \& Hewitt, N. M. (2000). Talking about leaving: Why undergraduates leave the sciences. Oxford: Westview Press.

[6] Tobias, S. (1990). They're not dumb, they're different: Stalking the second tier. Tucson: Research Corporation.

[7] Ceci, S. J. \& Williams, W. M. (Eds.). (2007). Why aren't more women in science? Top researchers debate the evidence. Washington, DC: American Psychological Association.

[8] Bystydzienski, J. M. \& Bird, S. R. (Eds.). (2006). Removing barriers: Women in academic science, technology, engineering, and mathematics. Bloomington \& Indianapolis: Indiana University Press.

[9] National Academy of Sciences, National Academy of Engineering, and Institute of Medicine of the National Academies. (2007). Beyond bias and barriers: Fulfilling the potential of women in academic science and engineering. Washington, DC: The National Academies Press.

[10] Byers, N. \& Williams, G. (Eds.). (2006). Out of the shadows: Contributions of twentieth-century women to physics. Cambridge, MA: Cambridge University Press.

[11] http://www.goldieblox.com/, Accessed 01.03.14.

[12] Larkin, T.L. (2010), Women's Leadership in Engineering. In K. O'Connor (Ed.) Gender and Women's Leadership: A Reference Handbook (Vol 2, pp. 689 - 699). Thousand Oaks, CA: SAGE Publications.

[13] LeBold, W. W. \& LeBold, D. J. (1998, March). Women engineers: A historical perspective. ASEE Prism, $30-32$.

[14]Zoli, C., Bhatia, S. K., Davidson, V., \& Rusch, K. (2008). Engineering: Women and leadership. San Rafael: Morgan \& Claypool.

[15] Gibbons, M. (2009). Engineering by the numbers. In Profiles of Engineering and Engineering Technology Colleges: 2008 Edition. Washington DC: ASEE.

[16] Hill, C., Corbett, C., \& St. Rose, A. (2010). Why so few? Women in Science, Technology, Engineering, and Mathematics Washington, DC: AAUW.

[17] Eccles, J. S. (2007). Where are all the women? Gender differences in participation in physical science and engineering. In S. J. Ceci \& W. M. Williams (Eds.), Why aren't more women in science? (pp. 199210). Washington, DC: American Psychological Association.

[18] http://www.forbes.com/sites/jeannemeister/2012/08/14/job-hopping-is-the-new-normal-formillennials-three-ways-to-prevent-a-human-resource-nightmare/. Accessed 01.04.14.

[19] http://www.unesco.org/new/en/fellowships/programmes/unesco-loreal-international-fellowshipsprogramme-for-young-women-in-life-sciences-2014/. Accessed 01.04.14. 


\section{Appendix A: Questions for Faculty and other Professionals}

1. The first question set is simply to collect some biographical information. My purpose in this is to allow me, after analyzing the set of interview responses, to explore potential intersections between responses.

a. What is your age or age range?

b. What is your educational background?

c. What is the highest degree you've attained?

d. What is your present position?

e. Can you provide me with a brief "story" leading up to the position you currently hold?

2. What first engaged you with the study of science (STEM) as an academic endeavor?

a. Based on your experience, what factors do you feel most shaped your decision to pursue a career in STEM?

3. There is presently an abundance of research that shows that the lack of role models, discouragement from the media, sex differences in cognitive skill, and unpleasant experiences related to gender-bias in the classroom have all been suggested as potential reasons why women tend not to pursue a career in Physics or other STEM fields. Do you feel that any of these factors played a role in your decision to or not to consider a career in STEM? In addition, were these factors a result of observations you made or were they a result of direct or indirect experiences?

4. What is the first image that comes to your mind when I say the word, "scientist"?

5. Do you perceive science (in general) to be a field that engages society? Why or why not?

6. Think back to when you made your choice for your current career path. Do you recall what your perceptions of the STEM field were at the time you made your choice?

a. Have your perceptions of STEM changed since the time you entered the field? If so, how have they changed?

7. Do you feel that mentorship is important? What has your mentorship experience been like?

a. Have you had a mentor or do you currently have someone mentoring you? Is this person male or female? What does this mentorship look like?

b. Do you currently mentor someone? Is this person male or female? What does your mentorship look like?

8. Based on your own experiences, what do you think about the process that individuals use to choose STEM over other areas?

a. Based on your experiences do you perceive there is presently a difference between how men and women make this decision?

b. If yes could you describe what your perception is regarding these differences?

c. Do you feel there was a gender difference in how individuals made their decisions at the time you made your own decision to enter the STEM field? If yes, how do you feel it affected you?

9. What is your opinion in terms of whether or not a gender gap exists between the number of male and female students and educators in STEM departments? In addition, what is your opinion in terms of whether or not a gender gap exists within professional STEM fields outside of academia?

a. If you believe a gap exists, what factors do you think might contribute to its cause?

10. Do you feel that presently there is something being done to address the perceived gender gap in STEM?

11. This gets to the end of the formal interview questions, are there any questions you had anticipated I would ask that I did not?

12. Are there any comments or last thoughts you would like to leave me with? 


\section{Appendix Part B: Questions for College Women and Men}

1. The first question set is simply to collect some biographical information. My purpose in this is to allow me, after analyzing the set of interview responses, to explore potential intersections between responses.

a. What is your age or age range?

b. What is your educational background?

c. What is your current major?

d. What is the highest degree you aspire to attain?

e. Do you presently have a job (internship, work-study, TA, etc.) that involves knowledge of science?

f. Can you provide a brief synopsis (i.e. about 2 minutes) of your "story" leading up to the place you are currently with your studies and/or your present job?

2. What factors do you feel most influenced your selection of your current major? (i.e. a teacher, a parent, a friend, enjoyment of math and science in high school, etc.)

a. In what way(s) did these factors influence your decision?

3. In general, what is your perception of a career in your intended field of study?

a. What do you see yourself doing after graduation?

4. What is the first image that comes to your mind when I say the word, "scientist"?

a. Do you perceive science (in general) to be a field that engages society? Why or why not?

5. In more general terms, how do you perceive a career in STEM?

6. The lack of role models, discouragement from the media, sex difference in cognitive skill, and unpleasant experiences related to gender-bias in the classroom have all been suggested as potential reasons why women tend not to pursue a career in Physics or other STEM field. Do you feel that any of these factors played a role in your decision to or not to consider a career in STEM? In addition, were these factors a result of observations you made or were they a result of direct or indirect experiences?

7. Do you feel mentorship is important? What has your mentorship experience been like?

a. Have you had a mentor or do you currently have someone mentoring you? Is this person male or female? What does this mentorship look like?

b. Do you currently mentor someone? Is this person male or female? What does your mentorship look like?

8. Based on your own experiences, what do you think about the process that individuals use to choose STEM over other areas?

a. Based on your experiences do you perceive there is presently a difference between how men and women make this decision?

b. If yes, could you describe what your perception is regarding these differences?

c. Do you feel there was a gender difference in how individuals made their decisions at the time you made your own decision to enter the STEM field? If yes, how do you feel it affected you?

9. What is your opinion in terms of whether or not a gender gap exists between the number of male and female students and educators in STEM departments? In addition, what is your opinion in terms of whether or not a gender gap exists within professional STEM fields outside of academia?

a. If you believe a gap exists, what factors do you think might contribute to its cause?

10. Do you feel that presently there is something being done to address the perceived gender gap in STEM?

11. Do you feel your perception of STEM in general has changed over time? If so, please expand on how it has changed.

12. This gets to the end of the formal interview questions, are there any questions you had anticipated I would ask that I did not?

13. Are there any comments or last thoughts you would like to leave me with? 